\title{
CORRIGENDUM
}

\section{Film deposition and transition on a partially wetting plate in dip coating - CORRIGENDUM}

\author{
Peng Gao, Lei Li, James J. Feng, Hang Ding and Xi-Yun Lu \\ doi:10.1017/jfm.2016.64, Published by Cambridge University Press, \\ 22 February 2016
}

Figure 5 of the published paper should be replaced by the figure shown below. The comparison between Figures 5 and 6 illustrates the important distinction between regimes II and III, with the formation of a Landau-Levich-Derjaguin film (figure 6) once the capillary number is sufficiently large.
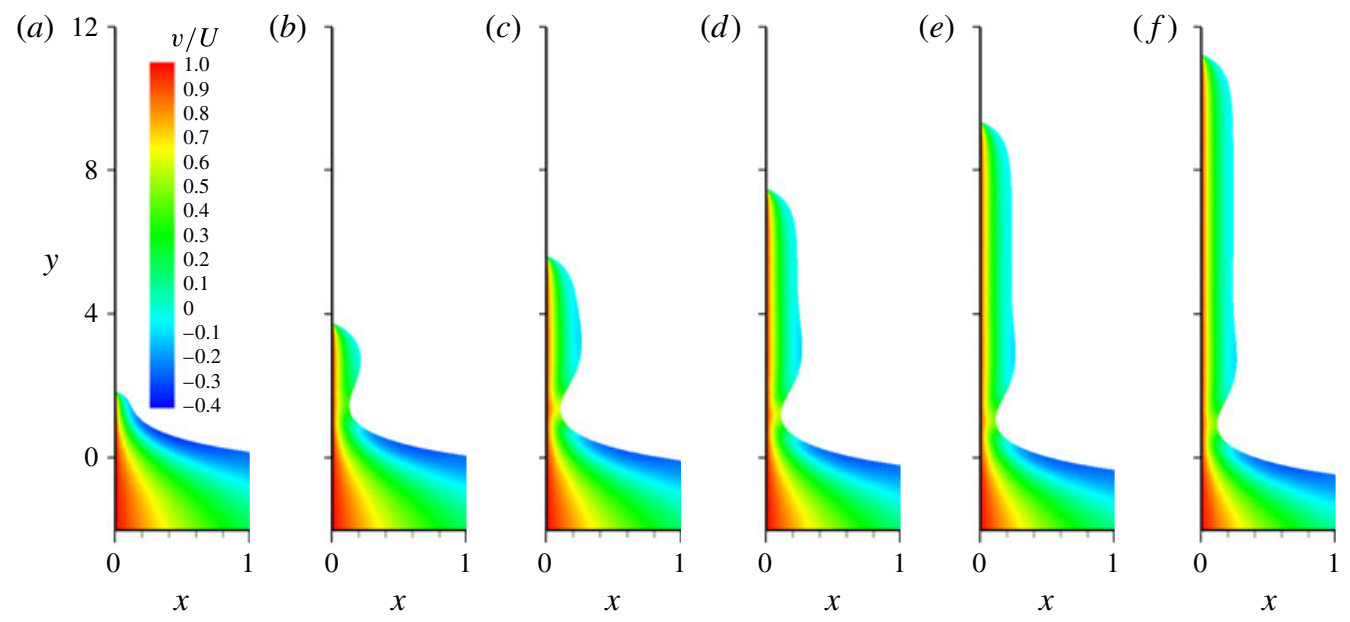

FIgURE 5. (Colour online) (Corrected) Time evolution of the interface for $C a=0.029$ in regime II. (a) Corresponds to $t=200$, and the time difference between successive panels is $\Delta t=200$, where time is scaled by $\mu_{1} \ell_{c} / \sigma$ and the same dimensionless time is used in the following figures. The lower fluid is coloured by the value of the vertical velocity $v / U$ to indicate the gravity-driven flow. The flow in the upper fluid is not shown for clarity.

\section{REFERENCE}

Gao, P., LI, L., Feng, J. J., Ding, H. \& LU, X.-Y. 2016 Film deposition and transition on a partially wetting plate in dip coating. J. Fluid Mech. 791, 358-383. 